\title{
Enhancing Lecture Presentation through Tablet Technology
}

\author{
Mirela Malin \\ Department of Accounting, Finance and Economics, Griffith Business School, Griffith University, Gold \\ Coast, Australia \\ m.malin@griffith.edu.au,
}

Dr Mirela Malin is a lecturer in the department of accounting, finance and economics within Griffith Business School. She has a research interest in how technology has influenced teaching in higher education and how blended learning techniques have been used to enhance student learning outcomes. She has presented at blended learning symposiums, international teaching conferences and has been a reviewer for journals and conferences in education and finance. Her publications include articles in the Journal of International Financial Markets Institutions and Money, Quarterly Review of Economics and Finance, Accounting Research Journal and JASSA among others.

\begin{abstract}
Purpose - The purpose of this paper is to describe a simple approach available to corporate finance instructors to enhance the lecture delivery through the use of 'digital ink' and tablet technology, to increase engagement during the lecture and enhance the classroom experience.

Design/methodology/approach - Selective quantitative and qualitative data from university course evaluations, student survey and examinations results were used to assess the effectiveness of this teaching technique.

Findings - Positive student satisfaction was documented with the majority of students finding that the new method of teaching has helped with their learning. While there was no substantial difference in the overall mean exam scores compared to previous teaching periods, there was an improvement in the ability of students to identify and summarize the different theories.

Originality/value - Technology has created both a progress and a decline in helping students learn. The original blackboard method of instruction was considered outdated when PowerPoint presentations became the main method of lecture delivery. However, the ability of instructors to work through problems progressively can be diminished in slide presentations. This paper shows how technology has facilitated a shift back towards the original 'chalk and talk' method of lecture delivery, where the 'chalk' has been replaced with 'digital ink' in an attempt to reinvigorate slide presentations and actively engage students more during the lecture.
\end{abstract}

Keywords - digital ink, iPad, app, lecture, student engagement.

Article Classification - Case study 


\section{Introduction}

In the last decade universities have been challenged by the digital revolution, forcing a shift in policy and academic practice towards greater integration (or 'blending') of traditional face-to-face and eLearning methods. Nowadays, eLearning is not only the responsibility of distance education institutions, but has been included in the student learning experience of campus-based institutions as well (Ellis et al., 2009). Schneckenberg (2009) states that the success of blended learning strategies in higher education depends on senior management's commitment to the development of academics' skills. As human resources within the tertiary institution, academics represent the 'face of the university' through their varied interactions with students and development of curriculum. Consequently, academics are the critical factor for structural eLearning innovation, and ultimately the success of eLearning within the tertiary sector. Not only must academics now embrace technology in every aspect of their teaching, but they must also find ways to keep students engaged and interested through the use of blended learning techniques.

The concept of student engagement refers to the way students interact with their institution in the process of learning and it depends upon how each student participates in educationally purposeful activities (Radloff and Coates, 2009). Student engagement refers not only to the time spent on an activity, but to the enhancement of the overall student learning and development experience. Radloff and Coates (2009: , p. 9) state that that the overall student learning experience depends also on the ability of institutions and staff to 'generate conditions that stimulate and encourage involvement'. Thus the instructors are an integral part of this process, requiring continuous development of new skill sets and new ways of thinking on how to make the learning process more stimulating (Moller et al., 2008).

While 'student engagement' is not a new idea and is generally a widely accepted construct for academics, knowing how to facilitate meaningful, stimulating and satisfying learning interactions within a virtual learning space is potentially a major obstacle academics face when designing eLearning curricula (Kuh, 2009). Kuh (2009) identifies the concept 'student engagement' to be a complex entity and not necessarily a solid one, rather it evolves as interpretations of the 'what and how' of teaching changes over time.

The pedagogical problem addressed in this paper relates to how student engagement can be increased by improving the content and the way the lecture is communicated (i.e., the 'what and how' of teaching) through the use of technology. More specifically, this paper presents an innovative way to deliver lectures in the higher education setting, particularly in finance courses, through the use of an iPad and a unique presentation application, called Explain Everything, which can be purchased through the App Store on the iPad. Preliminary observations alluding to the effectiveness of this presentation method will be discussed. 


\section{Theoretical Framework}

An appropriate pedagogical framework for learning and teaching with technology within business courses is the Community of Inquiry (Col) Framework presented by Garrison et al. (2010). According to this model, presented in Fig. 1, the educational experience of students is influenced by how technology affects: how we teach (the teaching presence) how students process the knowledge (the cognitive presence) and how students connect with their peers and teachers (the social presence). The application of technology in enhancing the delivery of lectures addresses two elements of Garrison's Community of Inquiry (Col) framework: Teaching presence and cognitive presence. Teaching presence includes design (creating innovative and challenging learning activities and environments), facilitation (providing new means for communication and interaction between students and teachers) and direct instruction (various ways of sharing and introducing information from diverse sources and forms with the help of emerging technologies) (Garrison and Akyol, 2009). Within the teaching element, technology is able to change the way academics teach thus causing an incremental change to pedagogy.

Insert Figure 1 Here

Garrison and Akyol (2009) describe cognitive presence in terms of four Practical Inquiry model phases proposed by Garrison et al. (2001): the triggering event (presentation of the problem), exploration (problems are explored by gathering information and discussion), integration (relevant information and ideas are brought together to solve the problem), and resolution (testing the proposed solutions). Within the cognitive element of the framework, technology, with the aid of teaching presence, helps the student develop a better understanding of the content, promotes higher order thinking and reflective learning and facilitates a better engagement with the course content. As Garrison and Akyol (2009) state: 'the key to cognitive presence is teaching presence as manifested through task specification and active facilitation or moderation'.

Garrison and Vaughan (2008) state that the key in engaging students to construct meaningful knowledge is found in the way students are stimulated and motivated to reflect on the material presented to them. The educational experience of students can be enhanced by integrating the three elements of teaching presence: design, facilitation and direction. The educational leader is thus responsible for providing the appropriate design, facilitation and direction that will structure, support and shape the students' learning experience Garrison and Vaughan (2008: , p. 32). Furthermore, Garrison et al. (2010) state that the three dimensions of teaching presence appear to help students through the four Practical Inquiry (PI) phases of the cognitive presence. Similarly, the teaching presence element is an important determinant in student satisfaction, perceived learning, and sense of community (Garrison and Arbaugh, 2007). Having established the importance of the teaching 
presence in the overall student learning experience and engagement, the attention is directed toward the factors that hinder or delay this process.

\section{Key Challenges Relating To Student Engagement}

While sustained attention in class is dependent upon a range of factors like time of day, motivation, emotion and enjoyment, earlier studies on attention span suggested that 'after 15 or 20 minutes the lecture loses its effectiveness even in transmitting information' (Frederick, 1986: , p. 44). However, a more recent review by Wilson and Korn (2007) found no evidence to support this idea. Although the average length of attention span has not been accurately established, there is a growing concern that student attention during lectures is declining. Since university classes typically run for 1 to 2 hours, and are often scheduled back-to-back, instructors are faced with the challenge of capturing and maintaining students' attention for long periods of time. This is especially difficult for subjects involving mathematical formulas or other dense/abstract concepts. Strategies like incorporating live demonstrations or visual aids in the lecture, requiring student participation on certain tasks, or integration of other student-centered approaches have the ability to increase attention, leading to longer-lasting retention of the presented information (Bunce et al., 2010).

Another issue faced by many instructors, especially in the areas of science, maths and business, is that the slide presentation method has a reduced capacity to keep students intrigued through the gradual and spontaneous revelation of elements of an idea or problem as the thinking process progresses. Business courses such as accounting, finance and economics, for example, involve instruction by showing how models, equations and graphs are structured (Scott, 2011). An important learning outcome in business courses is the ability of the students to apply into practice the theory and models learned by solving complex problems which require multiple step processes. The free hand method of lecture delivery allows instructors to begin with a simple conception of the problem and then add in more complex elements as students master the basic ideas. This method also sends a subtle signal to students that the lecture is a 'work in progress' rather than a pre-scripted monologue, allowing them greater scope for active involvement.

Thus the problem that presents itself is: how to increase the attention of students through careful design of the three elements of the teaching presence in such a way that helps students engage more in the cognitive processes. The approach to solve this problem is to change the way the content is delivered in class. By designing a new method of delivery or learning activity, the teacher plans how to engage the learner in a sustained and effortful cognitive activity that allows the knowledge or idea to be retained until it is needed next time (Laurillard, 2009). Thus, the teachers' design of the lecture is crucial, as it motivates the learners' effort to stay engaged and retain complex information. According to Shulman (1986) the ways of representing and formulating the subject or the pedagogical and content knowledge is important in determining how students access and comprehend the material 
presented to them. One way of making the content more accessible and comprehensible to the learner is by using technology (Mishra and Koehler, 2006).

\section{Targeted Pedagogical Improvement}

The traditional face-to-face instructional mode of education still remains the major delivery method of tertiary education. To create dynamic presentations with traditional lecture delivery tools, teachers can use the whiteboard but this involves frequently turning their back to the class and losing eye contact with the students, which can result in students disengaging from the lecture (Race, 2007). Similarly, Exley and Dennick (2009) state that presenting concepts on the whiteboard or blackboard is unproductive as often writing is illegible and difficult to see from the back of a lecture theatre, making the lecture an ineffective learning mechanism (Venema and Lodge, 2013). The introduction of lecture capture practices, where the lectures are recorded and made available to students at their leisure, has permitted students greater opportunity for reviewing content according to their individual needs. However, this creates another drawback with using the whiteboard in that any free hand drawing on this tool is not recorded by the standard lecture capture setup. Many lecture theatres are equipped with electronic data visualisers (or document cameras) that are connected to the lecture recording system. However, the use of this tool stops the flow of the explanation because of the need to switch between devices, which can be followed by a delay as one device shuts off and the other turns on, which in turn interrupts the learning process of students.

Teachers need to explore these conventional methods in the new context of digital learning and if necessary adapt the environment, task practice or the way concepts are articulated, to the students' needs. Good teaching commands an understanding of how technology relates to pedagogy and content. Mishra and Koehler (2006) state that there is a complex and fine relationship between what is learned and taught (content), the methods of teaching and learning (pedagogy), and technology. Not only do instructors have to know the subject they teach, but also how the content can be changed by the application of technology. Similarly, knowing how teaching might change as a result of implementing a particular technology is connected with the ability of the instructor to choose the appropriate tool that fits the subject.

Given the stated constraints faced by educators in business courses, the challenge is to incorporate the static slide presentation method, which is superior in the way it clearly structures and efficiently signposts the key points of the lecture, with the spontaneous use of a free hand drawing tool into a dynamic lecture presentation where all visual and auditory components can be efficiently recorded as well. This can be achieved through the use of tablet technology and 'digital ink' which combines elements of traditional whiteboard-based teaching and PowerPoint presentation to deliver a more dynamic and interactive classroom experience (Phillips and Loch, 2012). This way, the face to face traditional presentation can be transformed into a combined teacher/student collaborative experience 
where the lecture is constructed slide by slide. This activity was found to be valued not only by the students, but can be more rewarding for the instructor as well (Phillips and Loch, 2011). The use of iPad and 'digital ink' to solve problems on the presentation slides has the potential to improve student engagement and enhance retention of content. Anderson et al. (2007: , p. 60) state that 'digital ink is a natural medium for solving problems, not just reporting solutions'.

The 'Explain Everything' application combined with the iPad fulfils the criteria for the free hand drawing tool. Like a whiteboard, the application provides a blank white canvas, but now in electronic form on the screen of the iPad. This canvas can be drawn upon using a specially designed, rubber-tipped pen called a 'stylus'. PowerPoint presentations can be imported into the application and added to the canvas, where it then becomes possible to draw upon individual slides and on the areas of the canvas surrounding them. Once imported into the application, individual slides can also be increased or decreased in size and moved around the canvas using regular touchscreen finger gestures. Thus the application permits answers and solutions to be worked on (or around) the actual PowerPoint slides. Using the stylus important concepts can be highlighted and students' attention can be directed to the current subject matter being discussed. The ability to annotate slides in real time to clarify a point, introduce diverse ideas and show novel solutions provides dynamicity to the traditional slide-based presentation (Anderson et al., 2007). The PowerPoint slides act as a framework for the lecture, where the instructor can add live annotations and pose challenging questions (Tront, 2007). Iribe et al. (2010), specifically, have shown that learning can be improved by including hand-drawn diagrams on presentation slides. Most importantly the iPad can be plugged into the data projector (in a similar way to how you would plug in a laptop) so worked solutions are recorded in the same manner as the typical lecture presentation. Students can therefore revise not only the lecture slides but also the worked examples, diagrams or models that otherwise would not have been recorded if a traditional whiteboard had been used instead.

This is an important tool, especially in applied maths based courses such as corporate finance, as it has the ability to increase students' understanding and facilitate deep learning. In the second teaching semester of 2012 this tool was used to present all lectures for two undergraduate second and third year finance courses. Fig. 2(A) presents an example of a PowerPoint slide without 'digital ink' annotations, where the concept of 'firm valuation' based on the Modigliani-Miller capital structure theory is presented step by step. Fig. 2(B) shows the same slide which has been reduced in size to allow further notes and explanations on the model. Similarly, Fig. 2(C) shows a slide which presents the stages in the valuation of a target firm in a merger, while Fig. 2(D) shows the same instructions using formulas inserted on the blank slide during the delivery of the lecture.

Insert Figure 2 Here 
The implementation of this teaching application is straightforward and doesn't involve extensive effort. Since the PowerPoint slides are already prepared, they can be uploaded from Dropbox or any other site into the 'Explain Everything' application as shown in Figure 3. The files uploaded can have a ppt. extension, however to make sure formulas or certain symbols are retained it is recommended that the slides can be uploaded in a pdf. format.

Insert Figure 3 Here

The application not only allows the instructor to write on the slides, but also displays a number of features like laser pointer, insert text/picture/browser, or change the colour of the pen, as seen in Figure 4. Furthermore, the app contains a recording feature that lets the user record the entire lecture or just certain sections of the delivery even if the theatre or seminar room is not equipped with recording capabilities. Complete explanation of each feature, together with video tutorials can be found on http://www.explaineverything.com/.

Insert Figure 4 Here

The cost associated with the application of this tool is minimal. The app is available for purchase for $\$ 2.99$ USD and can be installed on a Mac or Android device. The price of a 'stylus' ranges from \$10\$35 AUD while the extension cable that connects the tablet to the lecture theatre console costs around \$25-\$35 AUD. The examples described in this paper have been conducted on an iPad 2. The results of introducing this initiative are described in the next section.

\section{Evaluation}

Assessing the effectiveness of this method of lecture delivery is vital in understanding whether it improves student engagement and overall learning. At the end of each semester, students are asked to formally evaluate the course and the teaching team by completing a survey with questions on a fivepoint Likert scale ranging from 'strongly agree' to 'strongly disagree'. To evaluate this teaching method, a statement relating to the use of digital ink during the lecture delivery was inserted in the general university survey. Table 1 presents the students' responses from the two undergraduate courses where this method of lecturing was used.

Insert Table 1 Here 
Overall, in the second year corporate finance course, which is a core subject for the accounting major, 60 students responded to the survey, representing $37 \%$ of the cohort, while in the third year course, a capstone course in the finance major, $38.7 \%$ of the students filled in the questionnaire. The implementation of this technology proved successful, in terms of student satisfaction, with the vast majority of each group ( $85.0 \%$ and $96.8 \%$ for $2^{\text {nd }}$ and $3^{\text {rd }}$ year, respectively) choosing 'strongly agree' or 'agree' in response to the statement: "The use of writing on the presentation slides to solve problems or emphasise points during the lecture in this course assisted my learning". Student comments in response to open-ended questions on the surveys were also positive, revealing a perception in students that this method of teaching increased their attention in class and enabled greater retention of knowledge. Some examples of comments from the open-ended questions include the following:

Use of iPad to write examples during lecture is ground-breaking - very good solution to lecture capture not recording the whiteboard.

The use of 'explain everything' was very effective.

I found the additional notes added by the lecturer on the slides during the lectures to be invaluable in gauging a good understanding of the formulas.

The use of writing on the slides during presentations was a FANTASTIC!!! Idea that I have suggested to other lecturers; it is very helpful.

The new technology which allows me to see everything you write on lecture capture is fantastic and a great learning tool, and really keeps me engaged.

While these subjective ratings by students are very encouraging, it is equally important to look for objective improvements in the learning outcomes. The second year corporate finance course, where more than half of the students enrolled are accounting majors, was selected for further analysis. Corporate finance, a core subject in the Bachelor of Commerce, is one of the courses that had assigned specific learning goals and objectives that need to be assessed as part of the accreditation by the Association to Advance Collegiate Schools of Business (AACSB). AACSB requires tertiary institutions to have a quality Assurance of Learning (AoL) framework for its programs where knowledge specific to the discipline and generic skills are achieved (AACSB, 2013). The Program Learning Objective (PLO) assigned to corporate finance was to 'demonstrate an understanding of major theories, models and tools' and was applied to the mid-semester exam. The curriculum mapping of the program indicated that this course is the only finance subject that students in the accounting major must complete, thus enabling certain theories and models like efficient market hypothesis and capital asset pricing model to be assessed. When mean exam scores were calculated for the study period when the new method was implemented (i.e., semester 2 2012) and the two consecutive study periods preceding it, there did not appear to be any substantial improvement in the mid-semester or the final exam results that could be attributed to the innovation (see Table 2). 
Table 3 provides further information on each group of students in the teaching periods investigated. 'Total fails' represents the overall failure rate due to a grade lower than $50 \%$, while 'other fails' measures course abandonment due to failure to sit all exams or non-submission of all assessment items (Phillips and Loch, 2011). Semester 22012 where the new teaching method was introduced displays a lower percentage of 'total fails' compared to the other two periods. Similarly, there is a reduction of $1 \%$ in the number of 'other fails' in the semester where interactive lectures were introduced. Because the course investigated in this paper is a 'core' in the program, the number of course abandonments is relatively low. The demographics show an even gender distribution across the semesters, with international students making up between $31-47 \%$ of students enrolments.

\section{Insert Table 3 Here}

Phillips and Loch (2011) investigates whether socio-economic status (SES) has an influence on student achievement, motivation and engagement with a course, concluding that there is a relationship between students who drop out and low SES. Using student postcodes at application time and Australian Bureau of Statistics (ABS) 2011 census data provided by the university, Table 3 shows only a relatively small percentage of low SES students in each semester. Nevertheless, semester 1 2012 where the 'other fails' are the highest at $4.7 \%$ has also the highest percentage of low SES students at $7 \%$ compared with the other two semesters. However, the Grade Point Average (GPA) breakdown for each period shows that semester 22012 where digital ink was used in the lecture has the highest number of students with low GPA and, at the same time, the lowest failure rate (The GPA score is the student's overall score as at the commencement of the course where 1 is the lowest and 7 is the highest).

Although Table 2 and 3 provide mixed results as to the effectiveness of the new teaching tool, closer inspection of the mid-semester exam results reveals an interesting pattern. The mid-semester exam questions could be divided based on two PLO criteria, into those assessing the student's ability to identify and summarise the correct theory and those assessing the student's ability to apply the theory to a scenario. For each question set students were categorised according to whether they scored between 0-49\% (unsatisfactory US), 50-64\% (satisfactory S), 65-74\% (good G), 75-84\% (very good VG) or $85-100 \%$ (excellent EX), according to the grading scale of the university. As can be seen in Figure 3 there was a distinctive pattern of improvement in the results for the purely theoretical questions, with a higher proportion of students scoring $65 \%$ or above and a lower proportion of students scoring below $65 \%$ compared to the previous two study periods for which data could be collected. 
Insert Figure 5 Here

This pattern of improvement was not replicated for the application questions. Figure 4 shows mixed results. Although, from semester 1, 2012 to semester 2, 2012 there was an increase in the percentage of students who performed excellent (EX) and good (G) of $3.18 \%$ and $5.5 \%$ respectively, the performance of students who performed very good (VG) and satisfactory (S) decreased by $2.3 \%$ and $8.5 \%$ respectively. This makes the findings difficult to interpret given that the free hand drawing strategy is supposed to specifically target application of theory through clearer elucidation of problem solving techniques.

Insert Figure 6 Here

Nevertheless, the implementation of this teaching method has been greatly appreciated by the students, who have requested this tool to be adopted in other courses, as well as by other academics teaching in the field of accounting and finance who have embraced this method of lecture delivery to keep students engaged and improve learning outcomes.

\section{Conclusion}

The purpose of this paper was to describe how tablet technology can be used to communicate lectures that keep students engaged and to present preliminary observations relating to the introduction of a new lecture delivery method. The two key success measures that were explored were: 1) student satisfaction, as reported in the formal course evaluations; and 2) exam performance, as compared with that of previous teaching periods. The student satisfaction ratings were very positive with the vast majority of students reporting that they found the new method to have helped with their learning. It would be interesting in future to ascertain a measure of comparative value in student perceptions. For example, how valuable do students find this method compared to a standard PowerPoint lecture or interactive practice questions or simply reading the textbook. When it came to exam performance, again, the results seemed generally positive. While there did not seem to be any substantial difference in the overall mean exam scores compared to previous teaching periods, there did appear to be a general improvement in the ability of students to identify and summarise the different theories. Though this improvement did not follow through on all performance categories in the application of theory, it is a solid first step, which can be built upon in future teaching periods. In conclusion, it is imperative for lecturers to continually update their skill sets to incorporate the new technologies available for enhancing student engagement. While it would be unwise to introduce the latest technologies without a pre-conceived pedagogical purpose, early observations do suggest that 
when the right tool is selected to match the characteristics of the content area then substantial student learning improvements can be achieved. 


\section{References}

Aacsb (2013) "AACSB Learning and Teaching Standard A5", http://www.aacsb.edu/accreditation/accounting/standards/2013/learning-andteaching/standard-a5.asp (accessed 26 September 2013)

Anderson, R., Anderson, R., Davis, P., Linnell, N., Prince, C., Razmov, V. and Videon, F. (2007) "Classroom Presenter: Enhancing Interactive Education with Digital Ink", Computer, Vol. September, pp. 56-61.

Bunce, D. M., Flens, E. A. and Neiles, K. Y. (2010) "How long can students pay attention in class? A study of student attention decline using clickers", Journal of Chemical Education, Vol. 87, pp. 1438-1443.

Ellis, R. A., Ginns, P. and Piggott, L. (2009) "E-learning in higher education: some key aspects and their relationship to approaches to study", Higher Education Research \& Development, Vol. 28, pp. 309-319.

Exley, K. and Dennick, R. (2009) Giving a lecture: From presenting to teaching, New York, US: Routledge.

Frederick, P. J. (1986) "The lively lecture: 8 Variations", College Teaching, Vol. 34, pp. 43-50.

Garrison, D. R. and Akyol, Z. (2009) "Role of instructional technology in the transformation of higher education", Journal of Computing in Higher Education, Vol. 21, pp. 19-30.

Garrison, D. R., Anderson, T. and Archer, W. (2001) "Critical thinking, cognitive presence and computer conferencing in distance education", American Journal of Distance Education, Vol. 15, pp. 7-23.

Garrison, D. R., Anderson, T. and Archer, W. (2010) "The first decade of the community of inquiry framework: A retrospective", Internet and Higher Education, Vol. 13, pp. 5-9.

Garrison, D. R. and Arbaugh, J. B. (2007) "Researching the community of inquiry framework: Review, issues and future directions", Internet and Higher Education, Vol. 10, pp. 157-172.

Garrison, D. R. and Vaughan, H. (2008) "Designing blended learning to create a community of inquiry (Chapter 3, pp. 31-48)", Blended learning in higher education: Framework, principles and guidelines. San Francisco, Jossey-Bass, pp.

Iribe, Y., Nagaoka, H., Kouichi, K. and Nitta, T. (2010) "Web-based lecture systems using slide sharing for classroom questions and answers", International Journal of Knowledge and Web Intellingence, Vol. 1, pp. 243-255.

Kuh, G. D. (2009) "What student affairs professionals need to know about student engagement", Journal of College of Student Development, Vol. 50, pp. 683-706.

Laurillard, D. (2009) "The pedagogical challenges to collaborative technologies", Computer-Supported Collaborative Learning, Vol. 4, pp. 5-20. 
Mishra, P. and Koehler, M. J. (2006) "Technological pedagogical content knowledge: A framework for teacher knowledge", Teachers College Record, Vol. 108, pp. 1017-1054.

Moller, L., Forshay, W. R. and Huett, J. (2008) "Implication for instructional design on the potential of the web", Tech Trends, Vol. 52, pp. 66-70.

Phillips, P. J. and Loch, B. I. (2011) "Building lectures and building bridges with socio-economically disadvantaged students", Educational Technology and Society, Vol. 14, pp. 240-251.

Phillips, P. J. and Loch, B. I. (2012) "Dynamic and interactive teaching with technology", Journal of Financial Education, Vol. 38, pp. 46-68.

Race, P. (2007) The lecturer's toolkit, London, UK, Routledge.

Radloff, A. and Coates, H. (2009) "Doing more for learning: Enhancing engagement and outcomes. Australasian Survey of Student Engagement Report", Camberwell: ACER.

Schneckenberg, D. (2009) "Understanding the real barriers to technology-enhanced innovation in higher education", Educational Research, Vol. 51, pp. 411-424.

Scott, R. H. (2011) "Tableau Economique: Teaching economics with a tablet computer", The Journal of Economic Education, Vol. 42, pp. 175-180.

Shulman, L. S. (1986) "Those who understand: Knowledge growth in teaching", Educational Researcher, Vol. 15, pp. 4-14.

Tront, J. G. (2007) "Facilitating pedagogical practices through large-scale tablet PC deployment", Computer, Vol. September, pp. 62-68.

Venema, S. and Lodge, J. M. (2013) "Capturing dynamic presentation: Using technology to enhance the chalk and talk", Australasian Journal of Educational Technology, Vol. 29, pp. 20-31.

Wilson, K. and Korn, J. H. (2007) "Attention during lectures: Beyond ten minutes", Teaching of Psychology, Vol. 34, pp. 85-89. 


\section{Enhancing Lecture Presentation through Tablet Technology}

Tables to be included in the body of the paper:

Table 1. Results of survey administered at the end of semester

\begin{tabular}{|c|c|c|c|c|c|}
\hline \multirow{2}{*}{$\begin{array}{l}\text { Question Asked } \\
\text { The use of writing on the }\end{array}$} & & \multicolumn{2}{|c|}{$\begin{array}{c}\text { Corporate Finance } \\
2^{\text {nd }} \text { year }\end{array}$} & \multicolumn{2}{|c|}{$\begin{array}{l}\text { Advance Corporate Finance } \\
\qquad 3^{\text {rd }} \text { year }\end{array}$} \\
\hline & & $n$ & $\%$ & $n$ & $\%$ \\
\hline \multirow{5}{*}{$\begin{array}{l}\text { presentation slides to } \\
\text { solve problems or } \\
\text { emphasise points during } \\
\text { the lecture in this course } \\
\text { assisted my learning }\end{array}$} & SA & 23 & 38.3 & 12 & 50 \\
\hline & A & 28 & 46.7 & 11 & 45.8 \\
\hline & $\mathbf{N}$ & 5 & 8.3 & 1 & 4.2 \\
\hline & D & 2 & 3.3 & 0 & 0 \\
\hline & SD & 2 & 3.3 & 0 & 0 \\
\hline Total & & 60 of 162 & $37 \%$ & 24 of 62 & $38.7 \%$ \\
\hline
\end{tabular}

Notes: 5pt Likert scale: SD Strongly Disagree, D Disagree, N Neutral, A Agree, SA Strongly Agree

Table 2. Mean and standard deviation scores for the mid-semester and end-of-semester exams for three consecutive study periods

\begin{tabular}{|c|c|c|c|c|c|c|}
\hline \multirow{2}{*}{ Study Period } & \multicolumn{3}{|c|}{ Mid-semester Exam } & \multicolumn{3}{c|}{ End-of-semester Exam } \\
\cline { 2 - 7 } & Mean & $S D$ & $n$ & Mean & $S D$ & $n$ \\
\hline Semester 2 2011 & 20 & 4.8 & 192 & 29 & 11.1 & 179 \\
\hline Semester 1 2012 & 20 & 4.9 & 170 & 30 & 10.4 & 159 \\
\hline Semester 2 2012 & 21 & 4.9 & 157 & 30 & 11.2 & 148 \\
\hline
\end{tabular}


Table 3. Student fails, demographics and educational background

\begin{tabular}{|ll|c|c|c|}
\hline Demographics & Sem2, 2011 & Sem1, 2012 & Sem2, 2012 \\
\hline Students Enrolled & 192 & 170 & 159 \\
\hline Fails & Total & $16.5 \%$ & $12.4 \%$ & $10.8 \%$ \\
& Other & $3.6 \%$ & $4.7 \%$ & $3.7 \%$ \\
\hline Gender & Male & $50 \%$ & $57 \%$ & $57 \%$ \\
& Female & $50 \%$ & $43 \%$ & $43 \%$ \\
\hline Citizenship & Australian or Resident & $53 \%$ & $69 \%$ & $61 \%$ \\
Status & International & $47 \%$ & $31 \%$ & $39 \%$ \\
\hline Socio-Economic & Low & $4 \%$ & $7 \%$ & $3 \%$ \\
Status & Medium & $41 \%$ & $54 \%$ & $47 \%$ \\
& High & $3 \%$ & $2 \%$ & $4 \%$ \\
& NA & $52 \%$ & $37 \%$ & $46 \%$ \\
\hline Grade Point & 1 to less than 3 & $4.7 \%$ & $2.3 \%$ & $6.3 \%$ \\
Average & 3 to less than 5 & $50.5 \%$ & $47.7 \%$ & $46.5 \%$ \\
& 5 to 7 & $28.6 \%$ & $29.4 \%$ & $28.3 \%$ \\
& NA & $16.2 \%$ & $20.6 \%$ & $18.9 \%$ \\
\hline
\end{tabular}




\section{Enhancing Lecture Presentation through Tablet Technology}

Figures to be included in the body of the paper:

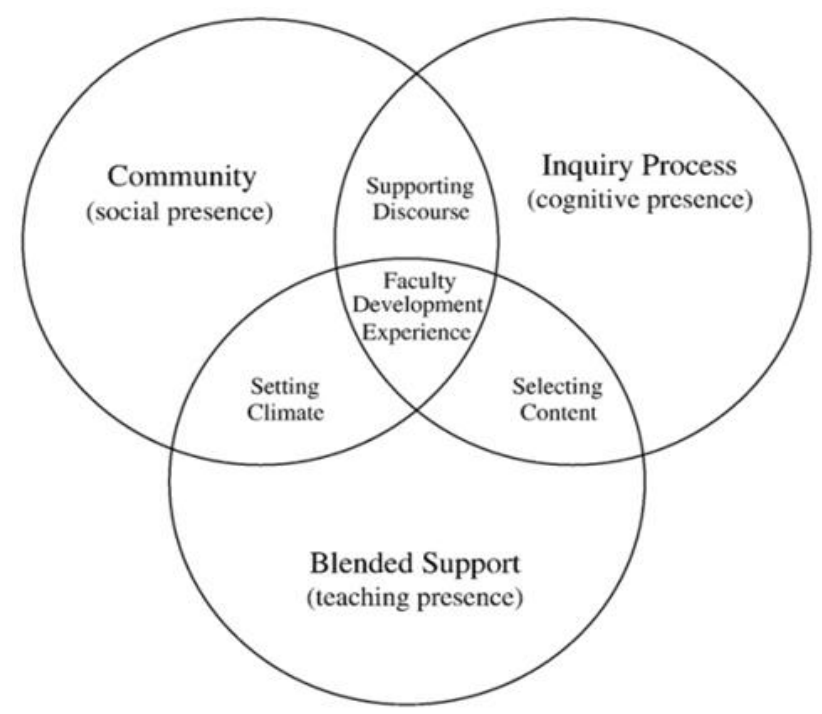

Figure1. Community of Inquiry Framework (Garrison et al., 2010) 


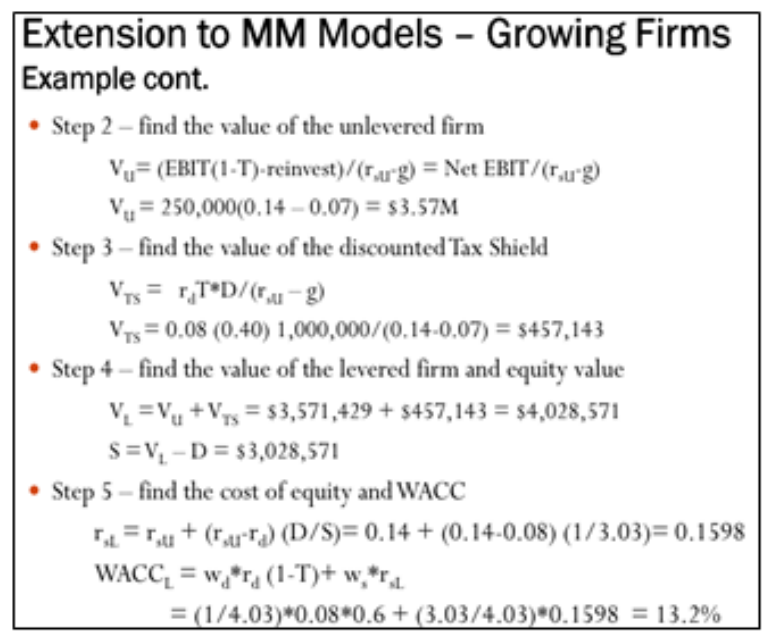

(A)

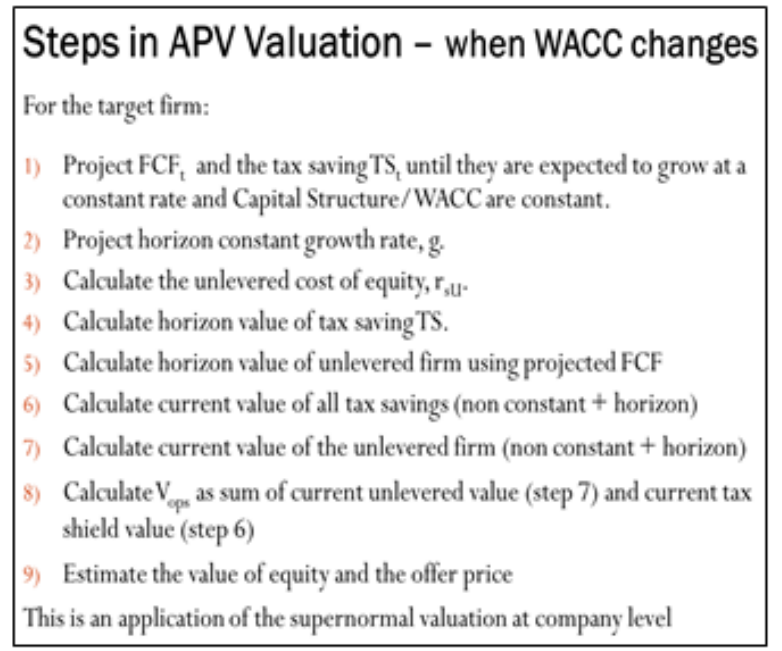

(C)

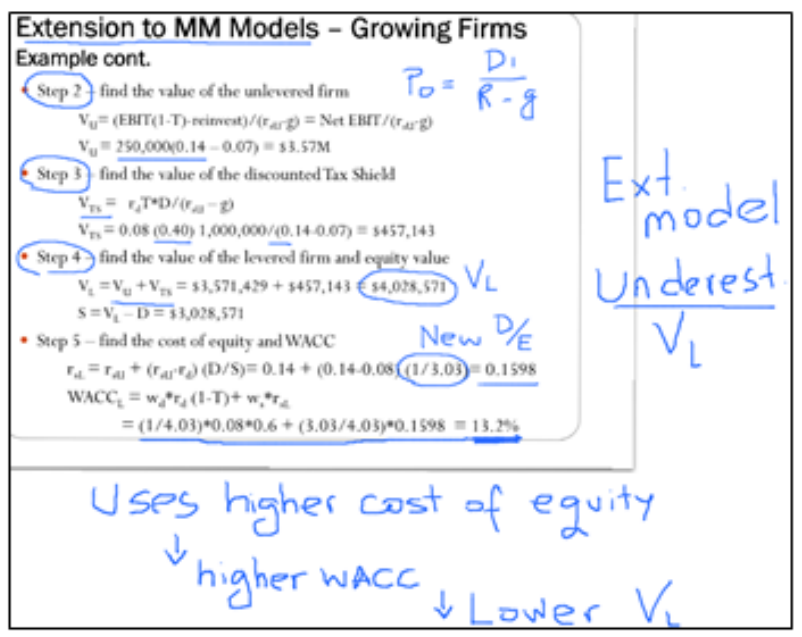

(B)

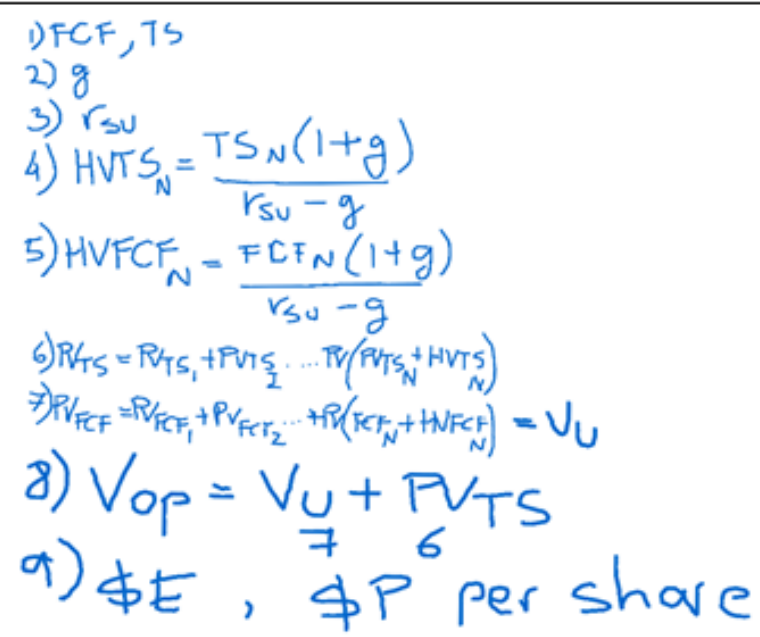

(D)

\section{Figure 2. Example of lecture slides}

Notes: Slide A contains no additional stylus notes while slide B shows the same slide which has been minimised with notes and important emphasis added. Slide C shows step by step word instructions on how to apply a model while slide D shows the same steps using the appropriate formulas drawn on a blank slide inserted during the presentation. 


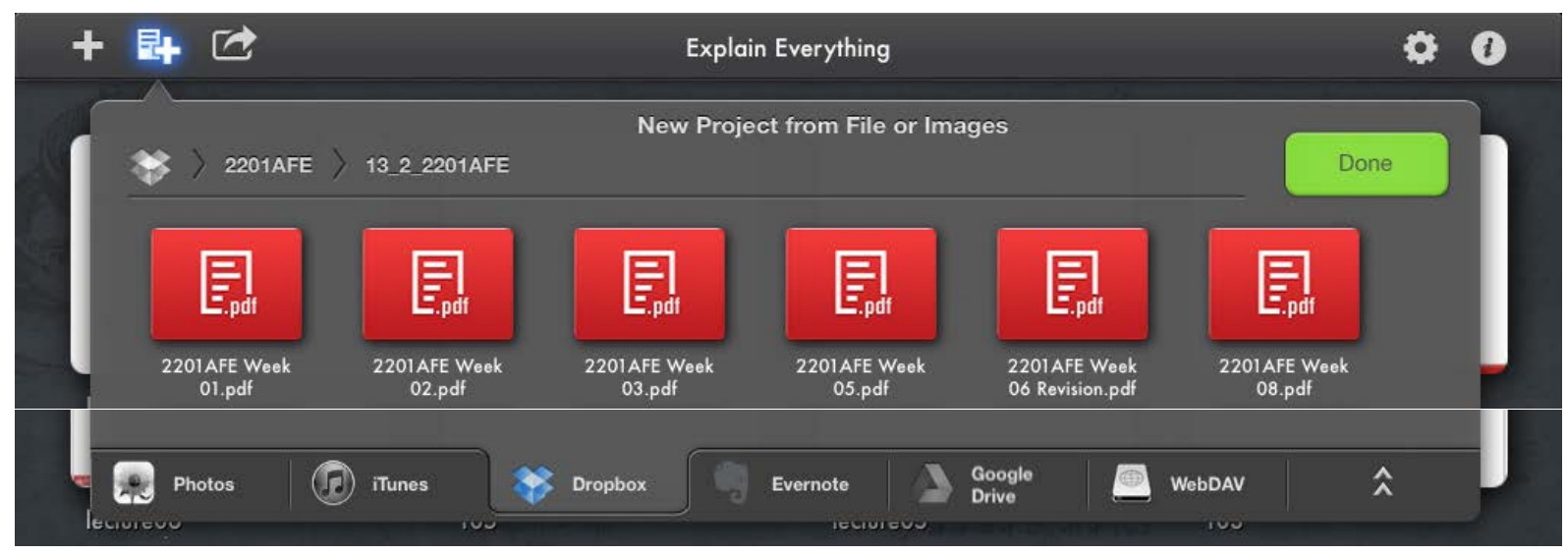

Figure 3. Uploading the lecture notes into the application

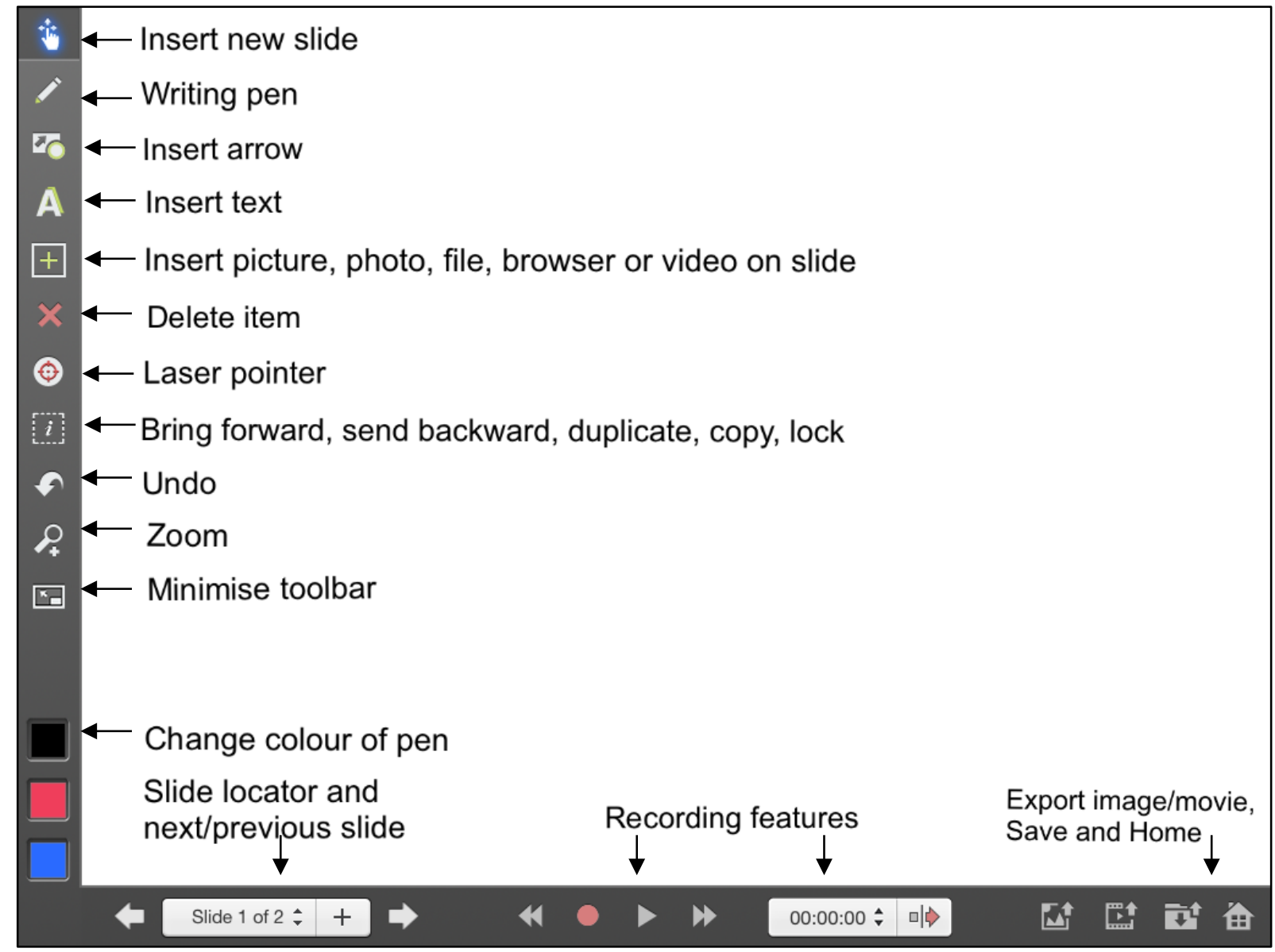

Figure 4. Features in the 'Explain Everything' app 


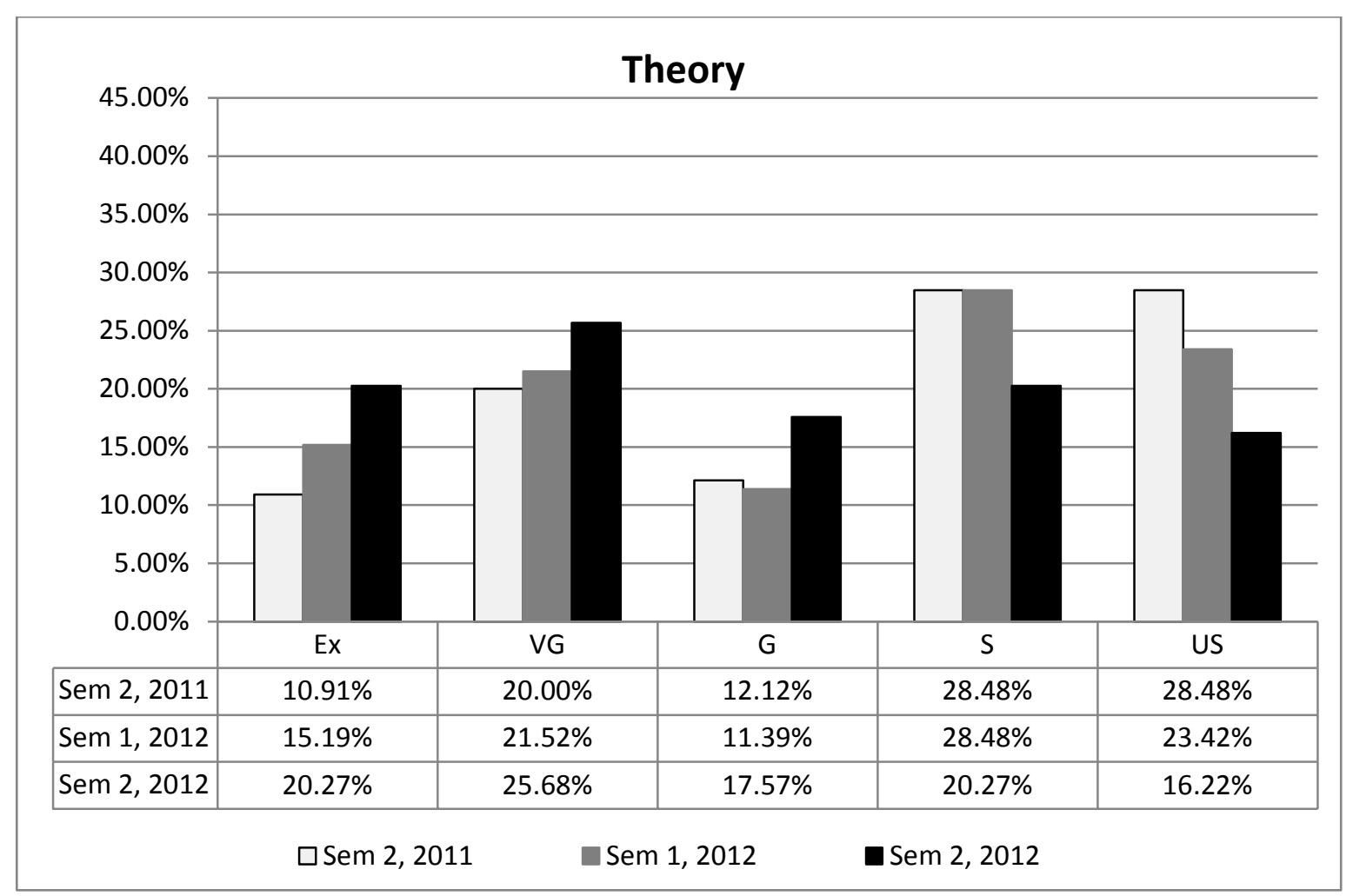

Figure 5. Percentage of students scoring in the different grade categories for the theoretical questions

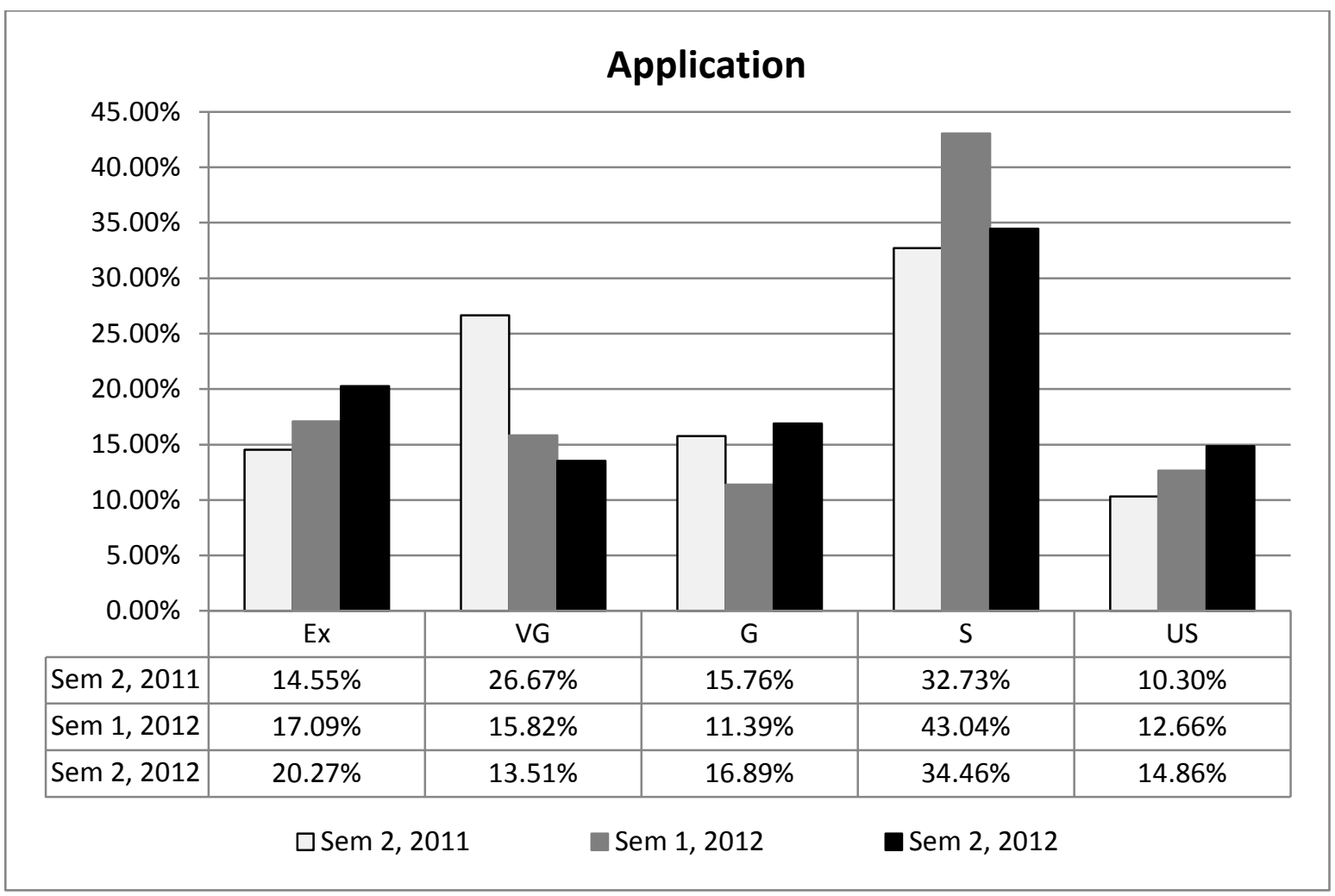

Figure 6. Percentage of students scoring in the different grade categories for the application questions 